Library Management, 2001, vol. 22, no. 1/2, p.80-85.

ISSN: 0143-5124

DOI: 10 1109/01435120110358970

http://www.emeraldinsight.com/Insight/viewContainer.do;jsessionid=D595C3D09216607FED575FDA0AF7B12F? containerType $=$ JOURNAL\&containerId $=121$

http://www.emeraldinsight.com/Insight/viewContentItem.do;jsessionid=D595C3D09216607FED575FDA0AF7B12

F? content $\mathrm{Type}=$ Article $\&$ hdAction $=\operatorname{lnkpdf} \&$ contentId=858998\&dType $=$ SUB \&history $=$ false

(C) 2001 MCB University Press

\title{
Copy cataloguers and their changing roles at the Ohio State University Library: a case study
}

\author{
Magda El-Sherbini
}

\begin{abstract}
The Ohio State University Libraries began the process of restructuring the Technical Services Department in early 1995. Changes that were introduced as a result of this process had a profound effect on the roles of professional and para-professional staff in the organisation. The author of this paper will outline the process of revamping the organisational structure of a large department in an academic library and will discuss the impact it had on the traditional roles assigned to librarians and staff in such a setting. The study will concentrate on copy cataloguers and their changing role in Technical Services.
\end{abstract}

\section{Introduction}

It would not be an exaggeration to state at the outset that the restructuring of the cataloging department at the Ohio State University Libraries has had a profound effect on the roles and responsibilities of librarians and technical staff in that organisation. Changes resulting from the restructuring process helped redefine the role of original and copy cataloguers as well as their support staff. In this paper I will outline the reorganisation process and discuss the impact it had on traditional staff roles.

The idea to reorganise technical services evolved over time, and began to take final shape around 1990. The process was initiated in response to the growing demands placed on the cataloging department and technical services. Restructuring emerged as the most effective method of maximising staff resources and providing internal opportunities for staff development and advancement.

The idea of redefining traditional roles of librarians and staff was articulated in an article written in 1991 by Jennifer Younger (Younger, 1991), former director for technical services at OSU, who wrote:

Designing, creating and coordinating a bibliographic access system that will continue into the next century requires a team approach to utilize the expertise of both professionals and para-professionals.

Ideas explored in this paper led to the initial planning and implementation of the restructuring scheme at OSUL. 
The author of the present article held positions of head of original cataloging and later head of the cataloging department, and worked with the director for technical services and head of the acquisitions department on planning and implementation of these changes.

Although not all the details of the outcome were clear at the beginning of the process, the directions set early on enabled us to succeed in achieving general objectives and goals. In addition to the long-range goals of maximising staff resources, there were also short-term objectives that we wanted to achieve in the process. These included:

- streamlining the workflow;

- increasing productivity of cataloguing in general and copy cataloguing in particular; and

- redirecting higher expertise to other functions of cataloguing.

In order to discuss the reorganisation process and the resulting changes in the roles of copy cataloguers at OSU, it will be helpful to present the background information. At the time when the restructuring decisions were being considered, the cataloging department consisted of approximately 60 professional librarians and technical staff. They were organised in seven sections:

(1) search and support staff;

(2) copy cataloguing;

(3) original cataloguing;

(4) maintenance;

(5) authority;

(6) special collections; and

(7) serials.

Each section generally represented various functions of technical processing assigned to the department.

At the end of the five-year restructuring process, the department employed 18 professional librarians and technical staff and ten half-time student assistants. Work is now being conducted in six sections that are organised along subject or format lines. The department retained all the cataloguing functions except for simple copy cataloguing, which was reassigned to the acquisitions department, and the special collections section, which became an independent department.

Changes in the role of copy cataloguers can best be seen when viewed against the process of restructuring of the original cataloguing, copy cataloguing and search sections of the cataloging department.

\section{The original cataloging section}

In the early 1990s some questions were raised about the role professional cataloguers played in the overall library operations. OSU librarians, who have faculty status and are in tenure track positions, were burdened with a wide range of academic, administrative and management responsibilities. At the same time they bore the primary responsibility for original cataloguing of all library materials. As the library found itself in the position of having to reallocate existing resources and seek new solutions, due in part at least to the shrinking library resources, the role of the cataloguing professional became part of the overall discussion. 
It was evident that professionally trained and experienced cataloguers constituted an important asset to the library. The administration had hoped to make better use of the acquired skills of professional cataloguers by redefining their primary areas of responsibility, placing the emphasising on more challenging and demanding management and training roles, and reducing their responsibility for direct title by title cataloguing. This became a viable option and came into focus partly in view of emerging alternatives to traditional methods of providing original cataloguing records. Options such as contracting out became available and gained a certain degree of acceptance in the library community at that time.

The original cataloging section (OCS) at OSU consisted largely of professional librarians who were responsible for original cataloguing. Many of them were recruited to perform original cataloguing of foreign language materials. Their responsibility was limited largely to original cataloguing and various functions outside the department, related to the promotion and tenure commitments associated with the faculty rank.

Primary cataloguing responsibilities of the OCS included:

- original cataloguing;

- complex copy cataloguing: K, M, L levels (which in some cases require extensive editing and enhancing of the record); brief records in OCLC (which require upgrading the record to full bibliographic record); assigning call numbers and subject headings (which need strong subject and expertise background).

Prior to the participation in the organisational restructuring, the author of this paper conducted two studies that explored alternative methods of original cataloguing (El-Sherbini, 1992, 1995). These included co-operative cataloguing, the use of temporary student help and contract cataloguing.

Results of these studies suggested that there were other, viable ways to perform original cataloguing. The possibility of using alternative ways to do cataloguing also opened the door to new initiatives.

Transformation of the original cataloging section began with the creation of a new highlevel staff position to perform original cataloguing of western language materials. This was the first staff position at the OSUL with the responsibility for original cataloguing. The position was filled by copy cataloguers. Ten graduate student assistants with foreign language expertise were hired to assist in performing original and copy cataloguing of foreign language materials (Arabic, Hebrew, Japanese, Chinese, Slavic, German, and Greek).

This shift of responsibility allowed the professional cataloguers to become more involved in management issues. They participated more actively in policy discussions, formulating and discussing cataloguing policy and contributed their experiences to library committee work. Besides their cataloguing responsibility, they also managed the workflow, and hired and trained graduate assistants. They were also involved in solving complex technical problems (such as call numbers, subject headings, solving conflict in the database and others), and negotiating contracts with vendors.

The OCS became a department with a combination of staff and professional librarians, where staff and student assistants performed original cataloguing, with librarians devoting more time to training and supervising functions.

This restructuring of the original cataloging section had a positive impact on productivity. The section was able to eliminate the longstanding backlogs in Arabic and western language materials as well as theses. The section kept current with the cataloguing of newly received 
materials. The success of this experiment led to the introduction of this management model in other sections of the library.

\section{The search section}

In the next phase of restructuring, a review of the search section was undertaken. Initially, the section consisted of an office manager, two classified staff and several student assistants. All were responsible for receiving books from the acquisitions department, searching the OCLC database, matching records and making printouts for copy cataloguers to use in cataloguing, and sorting materials by the type of records found (e.g. LC vs. member copy).

Members of the section also created brief records for those titles not found in OCLC and entered these records into the OSUL system. In addition, they were responsible for organising and managing the backlogs.

Section workflow and procedures were examined in preparation for possible restructuring and the following observations were made:

- There were redundancies in operations between the acquisitions department and the search section.

- The cost of searching was very high.

- Records found in the OCLC database were not used for copy cataloguing.

- There were substantial delays in processing, because most of the books that did not have copy were placed in the backlog for another search after six months.

To remedy the situation and introduce a more effective way to move materials through the system, it was decided to restructure the workflow and eliminate the unnecessary processing steps. This resulted in the merging of the search section with the copy cataloguing section. Most of the staff of the section joined the copy cataloguing section, while the head of the search section was reassigned to the original cataloguing section to perform original cataloguing.

The revised workflow allowed for the elimination of some of the redundancies in the workflow and resulted in reducing the time required to complete material processing. Merging of the two sections allowed the department to make better use of existing expertise and provide opportunities for staff advancement.

\section{Special collections}

During the reorganisation, the special collections section became an independent department. One copy cataloguer was reassigned there to perform copy cataloguing, while another copy cataloguer moved to special collections to fill the vacant LA2 position.

These two positions were lost to the cataloging department. The two staff members continued to perform duties similar to those which were part of their area of responsibility prior to the move. 


\section{Copy cataloguing}

At the start of the process, the copy cataloguing section consisted of civil service staff (para-professionals) members of various ranks. A professional librarian managed the section. The staff were responsible for very simple copy cataloguing, adapting copy from the OCLC database and performed copy cataloguing.

After all the changes in the department, the copy cataloging section ceased to exist and copy cataloguers were reassigned to the newly created sections, where they perform various functions ranging from original cataloguing to searching and processing of incoming materials.

Several factors effected copy cataloguing functions and copy cataloguing roles at the OSUL:

- A study of the feasibility of using OCLC's new Prompt Cat product showed that many of the approval plan western language materials have good copy in the OCLC database. Processing of these materials was moved to acquisitions, where it was done at the time of receipt.

- After reassigning some functions of the copy cataloging section to the acquisitions department, the copy cataloging section was disbanded.

- Classified staff at the LA1 level - the higher level copy cataloguers - were trained to perform some high level copy work which was previously handled by original cataloguers. This included assigning call numbers based on existing subject headings, cataloguing analytics and some problem solving.

- Some members of the search section started to perform simple copy cataloguing functions previously assigned to copy cataloguers only.

- Vacant professional librarian positions in the cataloging department were not reopened. It was determined that original cataloguing could be done by higher-level staff. A number of former copy cataloguers filled these vacant positions and were assigned responsibility for original cataloguing.

- Creation of new high-level staff positions in the cataloging department and the special collections department encouraged some copy cataloguers to apply for these positions and their vacant positions in copy cataloging were eliminated.

- Graduate student assistants were hired to perform various functions, which included everything from searching to producing records for foreign language materials.

All of the above factors contributed in various degrees to the emergence of a new role for copy cataloguers.

Many copy cataloguers assumed responsibilities formerly assigned only to the professionals. These responsibilities include:

- descriptive cataloguing;

- subject analysis;

- call number assignment;

- $\quad$ original cataloguing of literary works;

- original cataloguing of related editions;

- creating authority records for contribution to NACO;

- $\quad$ problem solving (example: fixing call number problems); 
- training graduate student assistants;

- work with graduate student assistants with language expertise, to create original cataloguing records;

- managing and organising special projects;

- supervising student assistants.

Many other technical functions formerly assigned to librarians (e.g. conflict between serial and monograph; Z call number; cutter number adjustment for all classes $\mathrm{M}, \mathrm{N}, \mathrm{P}$ ) could now be performed by copy cataloguers. Copy cataloguers perform this work for all formats except for theses and serials.

It is important to add that most of the graduate student assistants working in the cataloging department perform some of the same responsibilities, or work with copy cataloguers to accomplish this. They are being hired for their language and subject expertise.

Those copy cataloguers who assumed these new responsibilities moved to new positions in the civil service classification and their job titles changed from "copy cataloguer" to "cataloguer".

Some former copy cataloguers are now working in the acquisitions department with the receiving staff. After initial training in the new department they are performing the following tasks:

- searching titles in OSCAR when the piece arrives and reviewing against the existing bib and order records;

- searching new titles in OCLC to locate matching records for downloading and processing.

\section{Conclusion}

OSUL has always employed many qualified and experienced staff members and librarians. The library management team recognised that there were opportunities to utilise available skills more effectively. This was accomplished by reassigning responsibilities.

For copy cataloguers, it meant assuming responsibility for higher-level work (cataloguing). For professional librarians it meant moving away from cataloguing to management, training and other responsibilities.

Massive restructuring of the cataloging department at the OSUL had a profound effect on the classified staff involved in performing copy cataloguing. It provided the copy cataloguers with new challenges and opportunities to assume responsibilities previously reserved for professional librarians.

Those copy cataloguers who accepted the challenge moved into positions of higher responsibility and rank. They now perform original cataloguing (after position reclassification) and complex copy cataloguing as well as supervise student assistants.

Those copy cataloguers who moved to the acquisitions department were given the opportunity to perform some of the same functions. In addition, they were offered training in new areas. This enabled them to perform processing functions related to acquisitions work. As a result of this experiment at OSUL, copy-cataloguing positions as they existed formerly have changed significantly.

Training played a major role in the reorganisation process. It was handled internally by 
professional librarians who conducted most of the training sessions. The cataloging department created training guidelines for this purpose. Online tutorials were made available as part of the training package.

The training program was gradual as each step was introduced according to the degree of difficulty. It started with assigning call numbers, followed by assigning subject headings, MARC formats, descriptive cataloguing, and finally full descriptive cataloguing. Training of this magnitude requires a minimum of six months.

Staff reactions to the changes in the department were predictably varied. In the initial stages of the reorganisation process, there was a great deal of uncertainty and an overall lack of confidence in the process and its outcome. This is not surprising, given the scope of the restructuring and the nature of the changes being introduced. Such reactions can be attributed to the difficulty of articulating results of a long-range complex process such as this.

As the first positive results began to emerge, both the librarians and staff began to see benefits of the process and accepted the concept. This came very gradually, and in some cases required special reassurances and a lot of individual support. I must emphasise that the OSU reorganisation included all operations in the cataloging department and was not limited only to the copy cataloging section. Since the changes were so broad in scope, staff reaction should be viewed in that context.

At the very end of the process, when concrete benefits became apparent, most of the staff dramatically changed their attitudes and in general seemed very happy with the new arrangement and their new roles.

It is necessary to emphasise the importance of clear and consistent communication throughout the whole process. Keeping people well informed of what is being planned and what changes are taking place helps quite a lot. Throughout the process, staff were informed about its objectives and progress. This was achieved mainly through staff meetings.

This reorganisation helped to streamline the workflow, eliminated redundancies, improved productivity, simplified the administrative structure in the department and it was cost effective. The final result is a better use of individuals and their particular sets of skills and experience.

Most of the goals established at the outset of the process have been achieved.

Professional librarians and para-professional staff are now working together in teams where they can make better use of their experience and expertise. Improvements in the organisational structure of Technical Services led to better co-operation as cataloging and acquisitions departments are working together on technical service issues. Productivity has increased dramatically and many of the cataloguing backlogs have been eliminated or substantially reduced.

\section{References}

El-Sherbini, M. (1992), "Cataloging alternatives: an investigation of contract cataloging, cooperative cataloging, and the use of temporary help", Cataloging \& Classification Quarterly, Vol. 15 No. 4, pp. 67-88.

El-Sherbini, M. (1995), "Contract cataloging: a pilot project for outsourcing Slavic books at the State University Libraries", Cataloging \& Classification Quarterly, Vol. 20 No. 3, pp. 57-73

Younger, J. (1991), "The role of librarians in bibliographic access services in the 1990s", Journal of Library Administration, Vol. 15 No. 1-2, pp. 125-50. 